\title{
Crow-Fukase Syndrome Associated with Extramedullary Plasmacytoma
}

\author{
Susumu SHIRABE, Masao KishiKAWA*, Masanobu MinE, Takashige MiYAZAKI, \\ Hiromasa KURATSUNE and Kohji TOBINAGA**
}

\begin{abstract}
A patient with extramedullary solitary tumor had progressive sensory motor neuropathy, generalized pigmentation of skin, pretibial edema and gynecomastia. Serological examination of this patient showed monoclonal IgA- $\lambda$ gammopathy. Histologically, the tumor was defined as an $\operatorname{IgA}(\lambda$ type) positive extramedullary plasmacytoma by using peroxidase anti-peroxidase staining. The tumor was accompanied by angiofollicular lymphoid hyperplasia. Pathologically, it was recognized as an extramedullary plasmacytoma associated with Castleman's disease like changes, and was successfully treated by surgical resection, followed by irradiation.
\end{abstract}

Key words: IgA $\lambda$ monoclonal gammopathy, Polyneuritis

In 1956, Crow reported two patients with the characteristic findings of skin pigmentation, hyperhidrosis of palms and soles, severe peripheral neuritis, edema of ankles and plasma cell myeloma (1). In 1968, Fukase et al (2) described a Japanese patient showing the same clinical features of these cases and an association with an extramedullary plasmacytoma. Since then over one hundred cases have been reported in Japan $(3,4)$, however only three cases were associated with extramedullary plasmacytoma (5-7). One case had both a bone lesion and extramedullary plasmacytoma (6). In this paper, a patient with Crow-Fukase syndrome associated with an extramedullary plasmacytoma is reported. The clinical signs and symptoms of CrowFukase syndrome were markedly improved after surgical resection of the tumor, followed by irradiation.

\section{CASE REPORT}

An 83-year-old Japanese man first noted a left axillary mass in 1982. As the histological examination of this tumor showed no malignant features, the mass was not treated. In 1986, he developed numbness in the distal portion of the lower extremities, and the following year, edema of pretibial and ankle region, minimal pleural effusion and generalized pigmentation of skin. In late 1987, progressive walking difficulty and severe numbness of lower extremities appeared. A neurological examination on admission disclosed diffuse hyporeflexia in the four extremities and distal dominant sensory disturbance in the lower extremities which were attributed to polyneuritis. Generalized dark-brown skin pigmentation, gynecomastia, hyperhidrosis of palms and soles, pretibial pitting edema and pleural effusion were also observed.

The biochemical analysis of serum showed high titer of IgA (704 mg/dl), but titers of IgG and IgM were within the normal range. A monoclonal gammopathy of $\operatorname{IgA}-\lambda$ type was disclosed by using

From The Department of Internal Medicine, Isahaya Health Insurance General Hospital, Isahaya, *The Department of Pathology, Scientific Data Center for the Atomic Bomb Disaster, Nagasaki University School of Medicine, Nagasaki and ${ }^{* *}$ The Department of Surgery, Isahaya Health Insurance General Hospital, Isahaya Received for publication October 9, 1989; Accepted for publication September 17, 1990

Reprint requests should be addressed to Susumu Shirabe, MD, The Department of Internal Medicine, Isahaya Health Insurance General Hospital, Isahaya 854, Japan 
an immunoelectrophoresis technique. Bence Jones protein was not detected. Though the number of plasma cells detected by bone marrow aspiration was slightly higher $(3.8 \%)$ than the normal level, it was considered to be in the normal range of his age.

The radiographic skeletal bone survey did not demonstrate the existence of plasmacytoma. Bone scintigram also showed no abnormalities. The endocrinological study disclosed an increased testosterone titer $(90 \mathrm{ng} / \mathrm{dl})$ in peripheral blood. The titer was decreased to the normal level after treatment.

The electrophysiological study of the peripheral nerves showed slowing of the nerve conduction velocities and a reduced amplitude of nerve action potentials in the median, ulnar, sural and peroneal nerves. Teased fiber analysis of the sural nerve showed axonal degeneration (condition E) in $17 \%$ of myelinated fibers and segmental demyelination in $12 \%$. The number of myelinated fibers was moderately decreased $\left(5,044 / \mathrm{mm}^{2}\right)$ on morphometric analysis of transverse section.

The histological examination of the axillary tumor which was removed surgically confirmed it to be an extramedullary plasmacytoma with angiofollicular hyperplasia. Peroxidase anti-peroxidase staining showed monoclonal proliferation of plasma cells containing IgA- $\lambda$ chain immunoglobulin.

After surgical resection of the axillary tumor, gynecomastia and numbness of the lower extremities

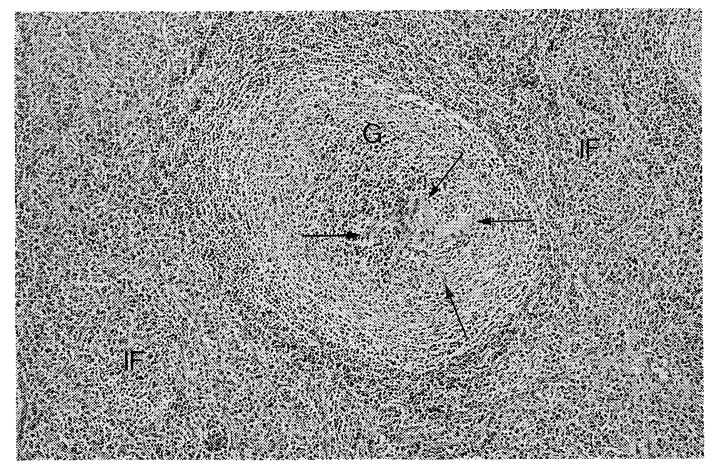

Fig. 1. Extramedullary plasmacytoma associated with Castleman's disease-like changes. Hyaline vascular changes with arborising capillaries (arrow), which penetrate the follicle center of small germinal centers, can be observed. Proliferation of numerous plasmacytes in the interfollicular spaces (IF) is seen. G indicates germinal center (Hematoxyline eosin stain, $\times 60)$. improved dramatically. Generalized skin pigmentation, hypesthesia of the lower extremities and pretibial edema were quite improved. CRP and M protein component were nearly normalized within one month. Despite the favorable clinical course after surgery, lymphorrhoea from the surgical wound including $3 \%$ of plasma cells was observed nearly for one month. Then the lesion was treated with 30 Gray of ${ }^{60} \mathrm{Co}$ irradiation. His walking difficulty was quite improved and pretibial edema disappeared completely during the period of irradiation.

\section{DISCUSSION}

Only four cases $(2,5-7)$ of Crow-Fukase syndrome have been reported to be associated with extramedullary plasmacytoma; one of these cases also had a bone lesion (6). The prognosis reported in three reports $(2,5,6)$ and that of our case was fairly good following surgical resection of the extramedullary tumor or irradiation therapy of the tumor. Because of the beneficial effect of surgical resection or irradiation therapy of the extramedullary plasmacytoma, it might be suggested that the extramedullary plasmacytoma plays an important role in the pathogenesis of Crow-Fukase syndrome. Peculiar histological changes, such as angiofollicular lymph node hyperplasia, resembling those of Castleman's disease were observed in the

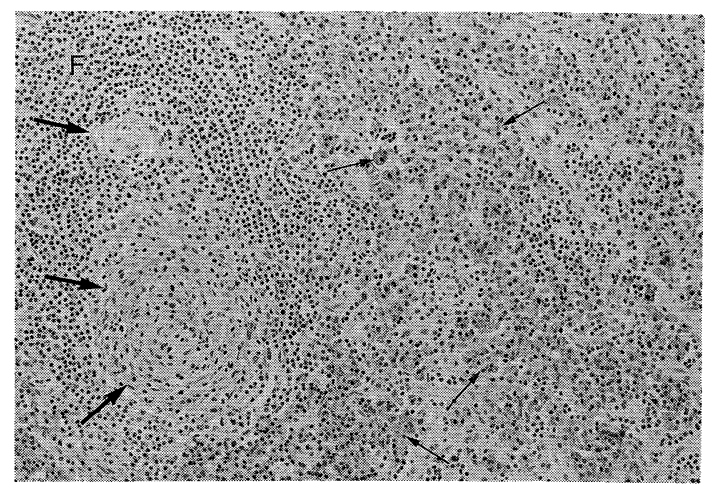

Fig. 2. Plasmacytes in the interfollicular space were specifically stained by anti- $\lambda$ antibody (small arrow). The concentrical proliferating vessels (big arrow) resemble the changes in Castleman's lymphoma. These findings indicate an extramedullary plasmacytoma associated with Castleman's lymphoma-like change. $F$ indicates lymph follicle (Anti- $\lambda$ antibody, PAP method, $\times 120$ ). 
extramedullary tumor of this case. These changes were not described in the previously reported cases of extramedullary plasmacytoma of Crow-Fukase syndrome. It may be that some cases of Castleman's disease are associated with polyneuritis, but not with such varying signs as in Crow-Fukase syndrome (8, 9). On the other hand, some cases of Castleman's disease have been reported to have monoclonal cell proliferation (9-11). But these cases had no neuropathy, skin pigmentation, edema or gynecomastia which were observed in our case.

Although Nakanishi et al (4) reported that Castleman's disease-like changes were observed in 19 of 30 Crow-Fukase syndrome cases which were examined pathologically using lymph nodes which were obtained by biopsy. These changes were observed in the small lymph nodes, which were less than $3 \mathrm{~cm}$ in diameter, and these were not found as a tumor but as generalized lymphadenopathy (4).

This is the first case of Crow-Fukase syndrome which is complicated with extramedullary plasmacytoma with features of Castleman's disease. Nakanishi et al (4) reported that the changes resembling those of Castleman's disease were found in 12 of 15 Crow-Fukase syndrome cases without bone lesions. Thus the changes resembling those of Castleman's disease may also have a relationship to such Crow-Fukase syndrome cases without bone lesions.

Here, a rare case of Crow-Fukase syndrome which was associated with extramedullary plasmacytoma with Castleman's disease like changes. This case was successfully treated by surgical resection and irradiation.

\section{REFERENCES}

1) Crow RS. Peripheral neuritis in myelomatosis. Br Med J 2: 802, 1956.

2) Fukase $M$, Shimpo $S$, Nishitani $H$, et al. Solitary plasmacytoma with polyneuritis and endocrine disturbances. Nippon Rinsho 26: 2444, 1968.

3) Takatsuki K, Sanada I. Plasma cell dyscrasia with polyneuropathy and endocrine disorder: clinical and laboratory features of 109 reported cases. Jpn J Clin Oncol 13: 543, 1983.

4) Nakanishi T, Sobue I, Toyokuma Y, et al. The CrowFukase syndrome: A study of 102 cases in Japan. Neurology (Cleveland), 34: 712, 1984.

5) Kimura H, Shichishima T, Tanaka T. A case of IgA $\lambda$-type extra-medullary plasmacytoma associated with polyneuropathy and other various symptoms. Jpn J Clin Hematol 20: 768, 1979.

6) Itoh S, Hirono S. Extramedullary $\operatorname{IgG}(\lambda)$ plasmacytoma with polyneuritis and pigmentation. Jpn J Clin Hematol 23: 870, 1982.

7) Ohkoshi N, Nakanishi T, Ozaki Y. The Crow-Fukase syndrome associated with extramedullary plasmacytoma - An autopsy case. Clin Neurol 27: 185, 1987.

8) Dennis $\mathrm{D}$, Weinburger MD, Bharat N, et al. Multicentric angiofollicular lymph node hyperplasia; a clinicopathologic study of 16 cases. Hum Pathol 16: 162, 1985.

9) Chan WC, Hargreaves H, Keller J. Giant lymph node hyperplasia with unusual clinicopathologic features. Cancer 53: 2135, 1984.

10) York JC, Taylor CR, Lukes RJ. Monoclonality in giant lymph node hyperplasia. Lab Invest 44: 77A, 1981.

11) Harris NL, Bhan AK. Immunohistology of Castleman's Disease: A Monoclonal Antibody Study. Lab Invest 52: 28A, 1985. 